\title{
Optimization and Doping of Reduced Graphene Oxide-Silicon Solar Cells
}

Lachlan J. Larsen, Cameron J. Shearer, Amanda V. Ellis, Joseph G. Shapter*

Flinders Centre for NanoScale Science and Technology, School of Chemical and Physical Sciences, Flinders University Bedford Park, GPO Box 2100, Adelaide, SA 5001, Australia

*joe.shapter@flinders.edu.au

Supplemental information: 

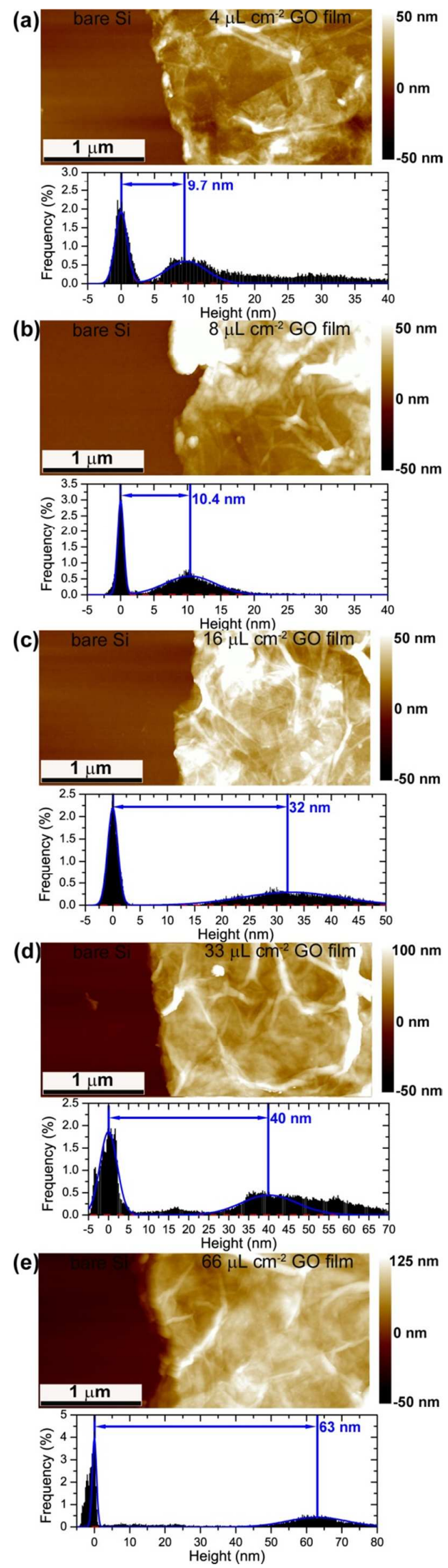
Figure S1: AFM height images and histograms of a (a) $4 \mu \mathrm{L} \cdot \mathrm{cm}^{-2}$ film, (b) $8 \mu \mathrm{L} \cdot \mathrm{cm}^{-2}$ film (c) $16 \mu \mathrm{L} \cdot \mathrm{cm}^{-2}$ film, (d) $33 \mu \mathrm{L} \cdot \mathrm{cm}^{-2}$ film and (e) $66 \mu \mathrm{L} \cdot \mathrm{cm}^{-2} \mathrm{GO}$ films. The flat area on the left of each image is the bare substrate exposed by the scratch.

(a)

$$
\text { bare Silicon RGO film }
$$

(b)

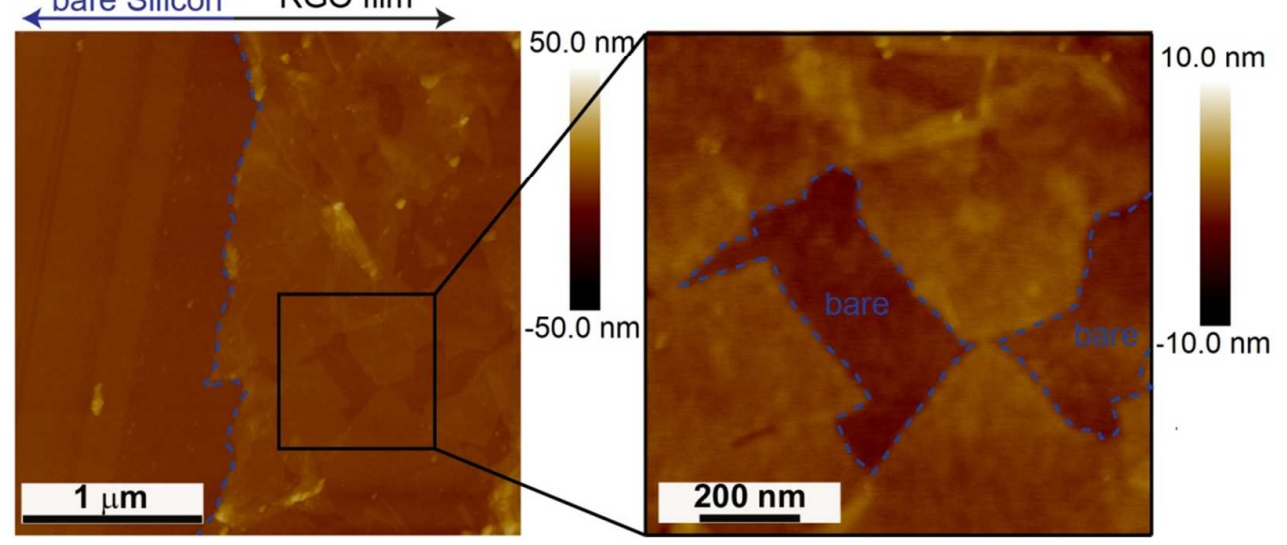

Figure S2: AFM image of $4 \mu \mathrm{L} \cdot \mathrm{cm}^{-2}$ film annealed at $400{ }^{\circ} \mathrm{C}$, with dashed lines added to image to show (a) bare silicon substrate area obtained using a scalpel and (b) areas of coating in RGO film which do not cover the substrate. 